\title{
Family Friendly and Occupational Commitment: the Mediation of Psychological Capital
}

\author{
Zhihua Lian ${ }^{\mathrm{a}}$, Lu Gao ${ }^{\mathrm{b}}$ \\ Xiamen University Tan Kah Kee College, Zhangzhou 363105, China

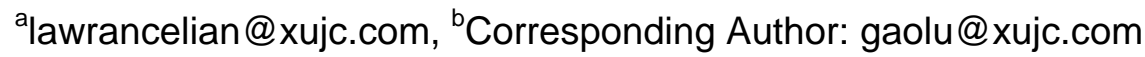

Keywords: Family-friendly, Occupational commitment, Psychological capital.

\begin{abstract}
Based on the social exchange theory, the purpose of this study is to explore how perceived family friendly affect occupational commitment and the mediating effect of psychological capital. We collected 456 pairing sample of employees and supervisors on the 9 province in China for statistical analysis. The finding of this study identified and tested the effects of antecedents and mediator. Results indicated that family friendly was positively associate with occupational commitment. Findings also indicated that psychological capital was a significant mediator of the relationship between family friendly and occupational commitment. Finally, the study provides management recommendations for the staff profession.
\end{abstract}

\section{Introduction}

In recent decades, the composition of families and the workforce have been changing along with the increasing numbers of dual-career couples, single-parent families, working mothers with young children and workers with eldercare responsibility in the workforce (Ko, Hur, \& Smith-Walter, 2013; Mulvaney, 2014). The shifting demographics of the workforce makes people find that it is increasingly difficult to balance family and work commitments for both male and female employees because they have substantial household responsibilities in addition to their work responsibilities (Caillier, 2016). Competing demands of work and home life not only increased hardships for employees' themselves, but also created difficulties for their employers (Marks, 1997), such as increase organizational costs associated with absenteeism, turnover and recruitment (Caillier, 2016). In response, some implement programs, called "family friendly programs", have been designed by organizations to assist employees to balance their work and family life (Allen, 2001).

Based on social exchange theory, employees are more likely to show positive attitudes and behavior (e.g. greater occupational commitment) when they perceive the organizational support (e.g., family friendly; Cropanzano, \& Mitchell, 2005). Indeed, many lectures have proven the direct relationship between family friendly and occupational commitment (e.g., Mulvaney, 2014). However, if an employee does not have intention to accomplish a task, all of the family friendly support would not necessarily yield a success. Nowadays, there are few research about the psychological mechanism through which family friendly facilitate occupational commitment (Luthans, Norman, Avolio, \& Avey, 2008). Therefore, the goal of this article is to fill in this blank and investigate how does family friendly lead to occupational commitment and the mediating effect of psychological capital on the relationship between family friendly and occupational commitment.

\section{Literature Review and Hypotheses}

\subsection{Family-friendly}

According to Frye and Breaugh (2004), Family friendly can be defined as "degree to which people perceive that their company has policies to personally assist them in integrating their work and family life". Similarly, Lee and Hong (2011) indicated that family friendly was a bundle of complementary benefits and programs designed to support employees to balance the conflicting demands of work and family life in today's fast-paced and complex environment. Until now, there is no generally accepted list of family friendly and the set of these programs have varied across different studies. For instance, 
Allen (2001) pointed out that family friendly included family care assistance (e.g., child-related benefits) and flexible work arrangement (e.g., flexible work hours, compressed work weeks). Mandeville, Halbesleben and Whitman (2016) divided family friendly into three categories, they were separately policies (e.g., flexible work arrangements), services (e.g., resource referral programs) and benefits (e.g., child care assistant). Besides this, Roberts et al. (2004) separated family friendly into traditional benefits and work life benefits. Traditional benefits address basic hygiene needs of employees, such as sick leave, pensions and health insurance, meanwhile work life benefits are designed to balance the diverse demands of employees' work, family and personal needs, such as flexible schedules, telework, elder care services, child care services, education and training needs as well as grocery stores and banking etc. Accordingly, our study suggests that family friendly should contain leave benefits (e.g., sick leave), dependent care services (e.g., elder care services, child care service), flexible work arrangement (e.g., flexible schedules, telework) and employee assistant programs (e.g., health insurance, banking).

\subsection{Psychological Capital}

Traditionally, many literatures have explored the significant influence of tangible capital (e.g., financial capital and tangible assets such as equipment and plant) on organizational performance, survival and development. Nowadays, managers recognize the importance not only of tangible capital but also of the intangible capital such as human capital, social capital and psychological capital. Human capital represents employees' experience, skills, knowledge and ideas. Social capital refers to resources of relationships, trust and contract networks (Luthans et al., 2004). Beyond these, psychological capital (PsyCap) can be viewed as an important construct in psychology, which focus on individual's emerging positive psychology movement (Zou, et al., 2016). In other words, financial capital describes "what you have", social capital defines "who you know", human capital captures "what you know", while psychological capital focuses on "who you are" and " what you intend to become" (Luthans, et al., 2004). Recently, the question about "how psychological capital affects organizational performance" received a growing sociological attention (Zou, et al., 2016). According to Luthans et al.(2007), psychological capital can be defined as "an individual's positive psychological state of development that is characterized by: (1) having confidence [self-efficacy] to take on and put in the necessary effort to succeed at challenging tasks; (2) making a positive attribution [optimism] about succeeding now and in the future; (3) persevering toward goals and, when necessary, redirecting paths to goals [hope] in order to succeed; and (4) when beset by problems and adversity, sustaining and bouncing back and even beyond [resiliency] to attain success". To sum up, psychological capital has been identified as the combination of the four positive psychological resources of self-efficacy, hope, optimism and resilience. The common characteristic of these four components is that they are independent of each other and can give clear representation in a single measurement model (Sahoo, \& Sia, 2015). For instance, Forbes (2005) measured the effects of self-efficacy independently and pointed out that entrepreneur self-efficacy contributes to new venture performance. Actually, these four psychological components work both independently and in tandem. For example, Luthans and Youssef (2004) linked the whole construct of these four components with employees' performance and found a positive relationship between them. Indeed, no matter the single component or the whole construct of psychological capital have been widely shown to predict a range of attitudinal outcomes and work-related behavioral, such as high employee performance (Luthans, \& Youssef, 2004), organizational citizenship behaviors (Avey, Reichard, Luthans, \& Mhatre, 2011) and occupational commitment (Sahoo, \& Sia, 2015; Shukla, \& Rai, 2015).

\subsection{Occupational commitment}

Occupational commitment can be viewed as the feelings that employees have towards their current organization, such as the acceptance of the organization's values and goals, a definite desire to stay with the organization and willingness to exert considerable effort on behalf of the organization (Kumasey, Bawole, \& Hossain, 2016). Becker (1960) illustrated that occupational commitment was a result of perceived loss of an individual's accumulated specific investments (e.g., effort, money, time) if the individual leave that organization. Mowday, Porter and Steers (1982) argued that an employee's psychological state of commitment to an organization is a consequence of an individual's behavior, 
which arises from the attachment to an employee's own freely chosen actions, a perceived obligation to follow through with these actions and the perceived costs of continuing or not continuing the actions (Mercurio, 2015).Meyer and Allen (1997) explored the depth and breadth of occupational commitment and developed a multidimensional model which consists of three components framework, involving affective commitment, continuance commitment and normative commitment. Affective commitment refers to employees' emotional bond and identification with their organization, which represents an employee's desire to remain in the organization. Continuance commitment reflects an awareness of the costs associated with leaving the organization and benefits associated with remaining in the organization (e.g., pay and promotion), which focuses on "the need to remain in the organization". While normative commitment reveals a feeling of obligation to continue employment (Meyer, \& Allen, 1991), which is distinguished from the other two components and emphasizes "an employee's formal and informal responsibility and his mind-set of an obligation to remain in the organization" rather than the "attachment to the organization"(Caillier, 2012). In recent meta-analysis, the unique qualities of each component have been better differentiated by investigating their relationships to antecedents, correlates and consequences in the workplace (Graham, \& Nafukho, 2010). Some authors pointed out that the concepts of three components are "qualitatively different" and affective commitment can be seen as the core of occupational commitment (Mercurio, 2015). Reid et al. (2008) confirmed the above point of view by using meta-analyses. They argued that affective occupational commitment is more strongly associated with the correlates of employees' attitudes and behaviors (e.g., job involvement, job satisfaction) than other two components. Actually, each of the three components works differently for different purposes and contributes to the overall understanding of how commitment influences work-related behavior (Graham, \&Nafukho, 2010). When investigating antecedents, no single component was affected more than another and all three components were found to correlate negatively with turnover intention and positively with job performance and organizational citizenship behavior (Meyer, et al., 2002).

\subsection{Family friendly and Occupational commitment}

The relationship between family friendly and occupational commitment can be explained by social exchange theory. Social exchange theory is one of the most influential conceptual paradigms for explaining organizational behavior, according to which the maintenance and development of all human relationships are based on the exchange of resources which are valued by the individuals who are interacting with one another (Aube, Rousseau, \& Morin, 2007). Social exchange can be divided into leader-member exchange (e.g., exchanges between supervisors and employees) and organizational support (e.g., exchange between organization and employees). For the latter, one of the most common ways organizations demonstrate their support for employees is by providing family friendly practices (Caillier, 2016). Based on social exchange theory, employees may establish social exchange relationship with their organization and show positive attitudes and behaviors (e.g., job satisfaction, greater occupational commitment) when organization cares about their wellbeing (Cropanzano, \& Mitchell, 2005). For example, organizations which provide paid sick leave enable their employees to address their health issues and urgent family issues without risking a voluntary or involuntary job separation. When employees perceived this support, they become less likely to quit a job and show more job satisfaction and loyalty to the organization (Hill, 2013). Similarly, individuals who perceived their organizations offered flexible work hours reported higher job satisfaction and occupational commitment (Scandura, \& Lankau, 1997). And employees are more committed to their organization when they are provided by leave benefits and time off programs (Mulvaney, 2014). Moreover, Caillier (2012) examined the interrelationships among family friendly programs, job involvement and occupational commitment by using a sample of 2010 employees from government agencies. They demonstrated that family friendly programs were positively associated to occupational commitment. Accordingly, no matter the single family friendly program or the composite bundle of family friendly can both prove the argument --- family friendly facilitate employee's occupational commitment positively. 


\subsection{Psychological capital as a mediator}

Quite a few empirical lectures have supported that there exist a direct relationship between family friendly and occupational commitment (e.g., Mulvaney, 2014). However, if an individual does not have the capacity and intention to accomplish a task, all of the family friendly support would not necessarily yield a success. Thus, it is crucial to investigate the psychological mechanism through which family friendly facilitate occupational commitment (Luthans, Norman, Avolio, \& Avey, 2008). As a positive psychological state, psychological capital has been used as a mediating variable by a lot of literatures to measure the effects of an antecedent factor on individual's work-related outcome (e.g., Avey, Wernsing \& Luthans, 2008; Jaffery, \& Qadeer, 2014; Pu, et al., 2016). For instance, Jaffery \& Qadeer (2014) investigated the relationship between organizational climate and organizational citizenship behavior and found that the impact of organizational climate on organizational citizenship behavior is not direct, which is mediated by psychological capital. They illustrated that organizational climate is one of the antecedents of psychological capital and only if supportive organizational climate converted into employee's psychological capital, the organizational citizenship behavior will occur. Similarly, luthans et al. (2008) found that when employees perceived support from their organization, they are more likely to generate characteristic of "hope" to try new methods to accomplish tasks. Likewise, when an employee make mistake under a supportive environment, they are more likely to feel "optimism" because they can continue to feel support from their organization and do not need to worry about too much punishment. Therefore, we can suppose that family friendly programs, as one kind of the most important organizational support, is positively related with psychological capital. On the other hand, Avey, et al. (2011) demonstrated that psychological capital has significant positive relationships with occupational commitment by analyzing the data of 12,567 employees in American service sector. Rego, et al. (2016) studied the mediating effects of psychological capital on occupational commitment and found that it positively facilitate employees' occupational commitment. According to above points of view, we may guess that family friendly is likely to be the antecedent of positive psychological capital, and psychological capital in turn leads to occupational commitment. In conclusion, we hypothesis as follows:

Hypothesis 1: Psychological capital mediate the relationship between family friendly and affective commitment.

Hypothesis 2: Psychological capital mediate the relationship between family friendly and continuance commitment.

Hypothesis 3: Psychological capital mediate the relationship between family friendly and normative commitment.

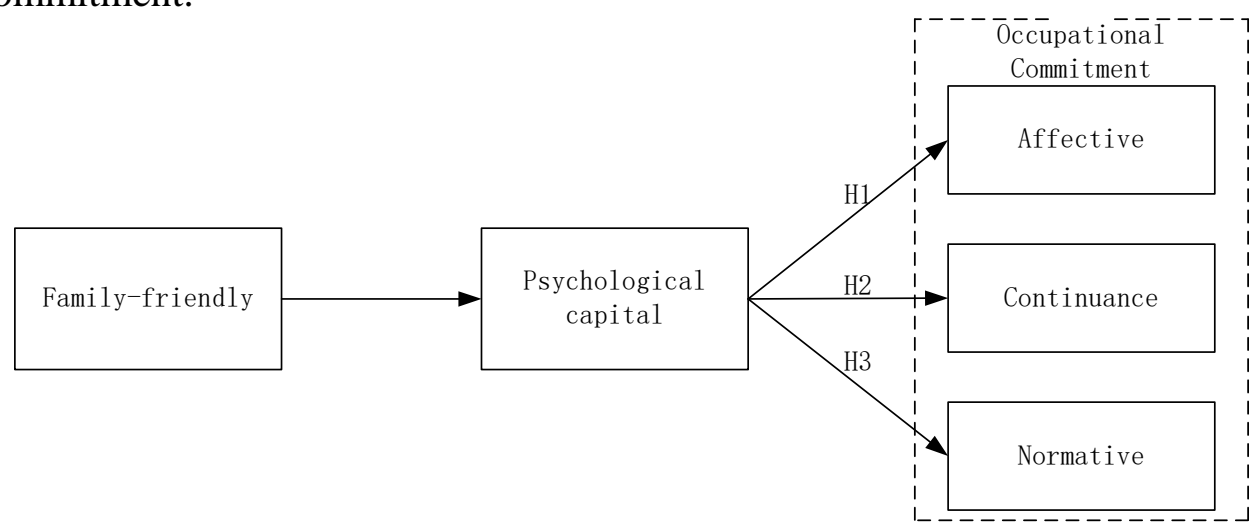

Figure 1 Research Framework

\section{Samples and procedures}

We conducted a field study to examine the proposed hypotheses in the setting of 9 provinces in China. We tested the proposed theoretical framework using data collected in two phases. In the first phase, all of the employees answered questions about their perception, family-friendly, psychological capital. In the second phase, supervisors answered questions about the employee`s occupational 
commitment. we used convenience sampling and occasional sampling method and tested the hypotheses with the sample survey. The questionnaire took about 15 min to complete and included a battery of psychological measures, as well as the demographic information of each participant. Each staff and supervisor was requested to fill out the questionnaire independently and put the completed survey in a sealed envelope. Results of the descriptive analysis showed that 456 questionnaires are valid questionnaires (83 percent). All subjects who joined in this study did on a voluntary basis with ensured confidentiality.

\section{Measurements}

\subsection{Family-friendly}

Family-friendly are employer-sponsored programs and policies that are designed to help employees manage work and personal life demands.We seleced the 17-item(Hammer et al.,2005) to represent family-friendly and practices. The sample include: (1)flexible benefits programs; (2)flextime; (3)reduced working hours for working parents; (4)family care leave; (5)childcare/parental leave; (6)telecommuting,etc.Responses to all scale items were rated on a 5 -point continuum(1=strongly disagree to 5=strongly agree). Cronbach's $\alpha$ for this scale in the current study was 0.910 .

\subsection{Psychological Capital}

Psychological capital was measured by the 24-item revised PsyCap Questionnaire (Luthans \& Youssef,2007) which covers 4 important states,namely,hope,optimism,self-efficacy and resiliency.The sample items include: (1)I am energetically pursuing my work goals; (2)when things are uncertain for me at work, I expect the best; (3)I feel confident while analyzing a long term problem to find a solution; (4)I feel I can handle many things at a time at this job. Respondents are asked to respond to each subscale on a five-point Likert-type scale ranging from 1 strongly disagree to 5 strongly agree. Cronbach's $\alpha$ for this scale in the current study was 0.898 .

\subsection{Occupaitonal Commitment}

In general, occupaitonal commitment include 3 dimensional conceptualization ,affective, continuance and normative. We made use of the 10 items from Allen and Meyer (1990) scale, the items being: (1) The faculty has a great deal of personal meaning for me; (2) I continue to work for the faculty as leaving would require considerable personal sacrifice; (3) I think that wanting to be a company man/wonman is still sensible. The Cronbach's $\alpha$ for this scale was 0.910 .

\subsection{Control Variables}

This study also controlled for 5 variables that might affect the hypothesized relationships, including gender, age, education, marital status and supervisor gender.

\section{Results and Discussion}

The descriptive statistics and intercorrelations among the variables are shown in Table 1. It summarizes the constructs and their corresponding measurement items (including sources of scale), Correlation, Composite reliability and AVE. We performed a CFA to check the reliability, validity, and uni-dimensionality of measurements used in this study. The results of CFA, as summarized in Table 1, show that the average variances extracted (AVEs) for all constructs were significantly higher than the stipulated criteria (50\%) and composite reliability values for all constructs were greater than 0.7. These figures thus demonstrated convergent validity of the measurement model. Moreover, all the inter-construct correlations in Table 1 were lower than the square root of the AVE, providing evidence of discriminant validity. Consequently, the measurement models passed both reliability and convergent/ discriminant validity checks.

Following the steps of the mediation procedure (Frazier, Tix, and Barron, 2004). While Frazier et al. illustrated the procedure for testing mediating effects with three variables (independent variable, mediator variable, and outcome variable), we also controlled for the effect of employee's gender, age, education and marital status. To test the third and last steps of mediation procedure, hierarchical 
regression analysis was done (Baron and Kenny, 1986). As a result, we tested the hypotheses through hierarchical multiple regression. Table 2 provides the estimated parameters and results of the hypotheses testing. For H1, family friendly was positively associated with affective commitment $(\beta=.243, \rho<.001)$. When psychological capital and family friendly were taken together in the regression analysis, the regression coefficient between family friendly and affective commitment is still significant $(\beta=.409, \rho<.001)$ and the mediating effect of psychological capital is also significant positive $(\beta=.155, \rho<.01)$. According to Baron and Kenny(1986), this result indcated significant mediation.Table 3 show the mediating effect of psychological capital between family friendly and continuance commitment.The results for Model4 indicate that family friendly had significant effects on continuance commitment $(\beta=.124, \quad \rho<.05)$, the mediation effect $(\beta=.119, \rho<.05)$.Thus,Hypotheses1 and 2 were supported. Morevoer, the last column of Table 4 indicates that Hypotheses 3 predicted that employees who are more satisfied with family friendly programs $(\beta=.091, \rho<.01)$ will have a higher level of normative commitment and psychological capital $(\beta=.232, \rho<.001)$ plays a mediation between family friendly and normative commitment. Thus, we found support for Hypothesis 3.

Table 1. Descriptive Statistics and Correlations

\begin{tabular}{|c|c|c|c|c|c|c|c|c|}
\hline & \multirow{2}{*}{ Construct } & Composite & \multirow{2}{*}{ AVE } & \multicolumn{5}{|c|}{ Correlation between latent constructs } \\
\cline { 6 - 9 } & Reliability & & & 1 & 2 & 3 & 4 & 5 \\
\hline 1 & Family-friendly & 0.892 & 0.508 & - & & & & \\
\hline 2 & Psychological Capital & 0.888 & 0.614 & $.533^{* *}$ & - & & & \\
\hline 3 & Affective Commitment & 0.850 & 0.600 & $.314^{* *}$ & $.369^{* *}$ & - & & \\
\hline 4 & ContinuanceCommitment & 0.864 & 0.561 & $.124^{*}$ & $.133^{*}$ & $.467^{* *}$ & - & \\
\hline 5 & Normative Commitment & 0.911 & 0.672 & .091 & $.198^{* *}$ & $.406^{* *}$ & $.638^{* *}$ & - \\
\hline
\end{tabular}

Table 2. Summary of Hierarchical Regression Analysis for mediation1

\begin{tabular}{|c|c|c|c|}
\hline \multirow{2}{*}{ Variables } & Model1 & Model2 & Model3 \\
\cline { 2 - 4 } & $\begin{array}{c}\text { Affective } \\
\text { commitment }\end{array}$ & $\begin{array}{c}\text { Psychological } \\
\text { capital }\end{array}$ & $\begin{array}{c}\text { Affective } \\
\text { commitment }\end{array}$ \\
\hline Family-friendly & $0.243^{* * *}$ & $0.531^{* * *}$ & $0.409^{* * *}$ \\
\hline Psychological capital & & & $0.155^{* *}$ \\
\hline $\mathrm{R}^{2}$ & $0.059^{* * *}$ & $0.282^{* * *}$ & $0.259^{* * *}$ \\
\hline $\mathrm{Adj}-\mathrm{R}^{2}$ & $0.056^{* * *}$ & $0.280^{* * *}$ & $0.255^{* * *}$ \\
\hline $\mathrm{F}$ & $22.567^{* * *}$ & $142.070^{* * *}$ & $62.823^{* * *}$ \\
\hline
\end{tabular}

Note $: * p<.05, * * p<.01, * * * p<.001$

Table 3. Summary of Hierarchical Regression Analysis for moderation2

\begin{tabular}{|c|c|c|c|}
\hline \multirow{2}{*}{ Variables } & Model4 & Model5 & Model6 \\
\cline { 2 - 4 } & $\begin{array}{c}\text { Continuance } \\
\text { commitment }\end{array}$ & $\begin{array}{c}\text { Psychological } \\
\text { capital }\end{array}$ & $\begin{array}{c}\text { Continuance } \\
\text { commitment }\end{array}$ \\
\hline Family-friendldy & $0.124^{*}$ & $0.531^{* * *}$ & 0.081 \\
\hline Psychological capital & & & $0.119^{*}$ \\
\hline $\mathrm{R}^{2}$ & $0.015^{*}$ & $0.282^{* * *}$ & $0.028^{* *}$ \\
\hline Adj-R & $0.013^{*}$ & $0.280^{* * *}$ & $0.022^{* *}$ \\
\hline $\mathrm{F}$ & $5.674^{*}$ & $142.070^{* * *}$ & $5.134^{* *}$ \\
\hline
\end{tabular}

Note $:{ }^{*} p<.05,{ }^{* *} p<.01,{ }^{* * *} p<.001$. 
Table 4. Summary of Hierarchical Regression Analysis for moderation3

\begin{tabular}{|c|c|c|c|}
\hline \multirow{2}{*}{ Variables } & Model7 & Model8 & Model9 \\
\cline { 2 - 4 } & $\begin{array}{c}\text { Normative } \\
\text { commitment }\end{array}$ & $\begin{array}{c}\text { Psychological } \\
\text { capital }\end{array}$ & $\begin{array}{c}\text { Normative } \\
\text { commitment }\end{array}$ \\
\hline Family-friendldy & $0.091^{* *}$ & $0.531^{* * *}$ & -0.058 \\
\hline Psychological capital & & & $0.232^{* * *}$ \\
\hline $\mathrm{R}^{2}$ & $0.008^{* *}$ & $0.282^{* * *}$ & $0.041^{* * *}$ \\
\hline Adj-R & $0.006^{* *}$ & $0.280^{* * *}$ & $0.036^{* * *}$ \\
\hline $\mathrm{F}$ & $3.004^{* *}$ & $142.070^{* * *}$ & $7.788^{* * *}$ \\
\hline
\end{tabular}

Note : $* p<.05,{ }^{* *} p<.01,{ }^{* * *} p<.001$.

We tested three hypotheses. First, that family friendly would be positively associated with affective commitment and psychological capital plays a role of mediating effect between family friendly and affective commitment; second, that psychological capital would be a mediating effect between family friendly and continuance commitment; and third, that psychological capital also plays a role of mediating effect between family friendly and normative commitment. Following the procedure recommended by Baron and Kenny (1986) and Ming R,W(2010), we tested the hypotheses with a sample of 456 full-time employees and 100 supervisors in Chinese. Our results support the hypothesized relationships.

\section{Research Limitations and Future Research Directions}

Although this study contributes to the literature by delineating the impacts of family friendly on occupational commitment and perceived psychological capital and describing the mediating effects of psychological capital, some limitations exist that should be addressed in future research. First, we measured family friendly, psychological capital through self-reporting; thus, common method variance might have inflated the relationships between those variables. Although Harman`s one factor test indicates that CMB is not serious threat to this study`s findings, the relationships among independent variables and dependent variables should be interpreted with caution. Second, our sample makes use of groups from a single industry company. Thus, the generalizability of our results needs to be tested by future replications in other service settings. We suggest that future researchers evaluate the results of this study by looking at different service settings. In addition, further research can expand this study framework and include other direction as possible moderators of the relation between family friendly and job-related behaviors. Potential variables may include employment ability, job involvement and deviant behavior.

\section{Acknowledgements}

This research was supported by Humanity and Social Sciences Research Foundation of Ministry of Education of China (15YJC630069), Sciences Research Talents Project Fund for Outstanding Young Teachers in Fujian Higher Education Institutions, China(2016023).

\section{References}

[1] N. Allen and J. Meyer, The measurement and antecedents of affective, continuance and normative commitment to the organization, Journal of Occupational Psychology 63 (1990), no. 1, $1-18$.

[2] T. Allen, Family-supportive work environments: The role of organizational perceptions, Journal of Vocational Behavior 58 (2001), no. 3, 414-435.

[3] C. Aube, V. Rousseau and E. M. Morin, Perceived organizational support and organizational commitment: The moderating effect of locus of control and work autonomy, Journal of Managerial Psychology. 22 (2007), no. 5, 479-495.

[4] J. Avey, R. Reichard, F. Luthans and K. Mhatre, Meta-analysis of the impact of positive 
psychological capital on employee attitudes, behaviors, and performance, Human Resource Development Quarterly 22 (2011), no. 2, 127-152.

[5] H. Becker, Notes on the concept of commitment, American Journal of Sociology 66 (1960), no. 1, 32-40.

[6] J. Caillier, Does satisfaction with family-friendly programs reduce turnover? A panel study conducted in U.S. Federal agencies, Public personnel Management 45 (2016), no. 3, 284-307.

[7] R. Eisinga, C. Teelken and H. Doorewaard, Assessing Cross-National invariance of the Three-Component model of organizational commitment: A Six-Country study of european university faculty, Cross-Cultural Research 44 (2010), no. 4, 341-373.

[8] N. K. Frye and J. A. Breaugh, Family-friendly policies, supervisor support, work-family conflict, family-work conflict, and satisfaction: A test of a conceptual model, Journal of Business and Psychology, 19 (2004), no. 19, 197-220.

[9] H. Hill, Paid sick leave and job stability, Work \& Occupations 14 (2013), no. 2, 143-173.

[10]H. Jaffery and F. Qadeer, Mediation of psychological capital between organizational climate and organizational citizenship behavior., Pakistan Journal of Commerce and Social Sciences 8 (2014), no. 2, 453-470.

[11]J. Ko, S. Hur and A. Smith-Walter, Family-friendly work practices and job satisfaction and organizational performance: Moderating effects of managerial support and performanceoriented management, Public Personnel Management 42 (2013), no. 4, 545-565.

[12]S. Lee and J. Hong, Does Family-Friendly policy matter? Testing its impact on turnover and performance, Public Administration Review 71 (2011), no. 6, 870-879.

[13]Z. H. Lian and B. Wang, "Family-friendly, role stress and innovation behavior: Assessing their effects on social enterprise employee base on market orientation," International Conference on Engineering Management and Industrial Engineering, EMIE 2014, Xiamen, China, 2015, pp. 217-220.

[14]F. Luthans, B. Avolio, J. Avey and S. Norman, Positve pshychological capital: Measurement and relationship with performance and satisfaction, Personnel Psychology 60 (2007), no. 3, 541-572.

[15]F. Luthans, K. Luthans and B. Luthans, Positive psychological capital: Beyond human and social capital, Business Horizons 47 (2004), no. 1, 45-50.

[16] M. Marks, Party politics and family policy: The case of the family and medical leave act, Journal of Family Issue 18 (1997), no. 1, 55-70.

[17]J. P. Meyer and N. J. Allen,,A three-component conceptualization of organizational commitment., Human Resource Management Review (1991), no. 1, 61-98.

[18]M. Mulvaney, Leave programs/time off and work-stress family employee benefits programs, organizational commitment, and self-efficacy among municipal employees, Public Personnel Management 43 (2014), no. 4, 459-489.

[19]J. Pu, H. Hou, R. Ma and J. Sang, The effect of psychological capital between work-family conflict and job burnout in Chinese university teachers: Testing for mediation and moderation, Journal of Health Psychology (2016), 1-9.

[20]F. Qadeer and H. Jaffery, Mediation of psychological capital between organizational climate and organizational citizenship behavior., Social Science Electronic Publishing (2014), no. 8, 453-470.

[21]B. Sahoo and S. Sia, Psychological capital and organizational commitment: Nature, Structure and Relationship in an Indian sample, Asia-Pacific Journal of Management Research and Innovation 11 (2015), no. 3, 230-244.

[22]T. Scandura and M. Lankau, Relationships of gender, family responsibility and flexible work hours to organizational commitment and job satisfaction, Journal of Organizational Behavior 18 (1997), no. 4, 377-391.

[23]L. Zhi-hua and Z. Ling, Supervisor support, job stress and employees`innovative behavior, Modern Finance (2016), no. 8, 91-101. 